Document downloaded from:

http://hdl.handle.net/10251/70458

This paper must be cited as:

Albors Garrigós, J.; Rincón Díaz, CA.; Igartua López, Jl. (2014). Research technology organisations as leaders of R\&D collaboration with SMEs: role, barriers and facilitators. Technology Analysis and Strategic Management. 26(1):37-53. doi:10.1080/09537325.2013.850159.

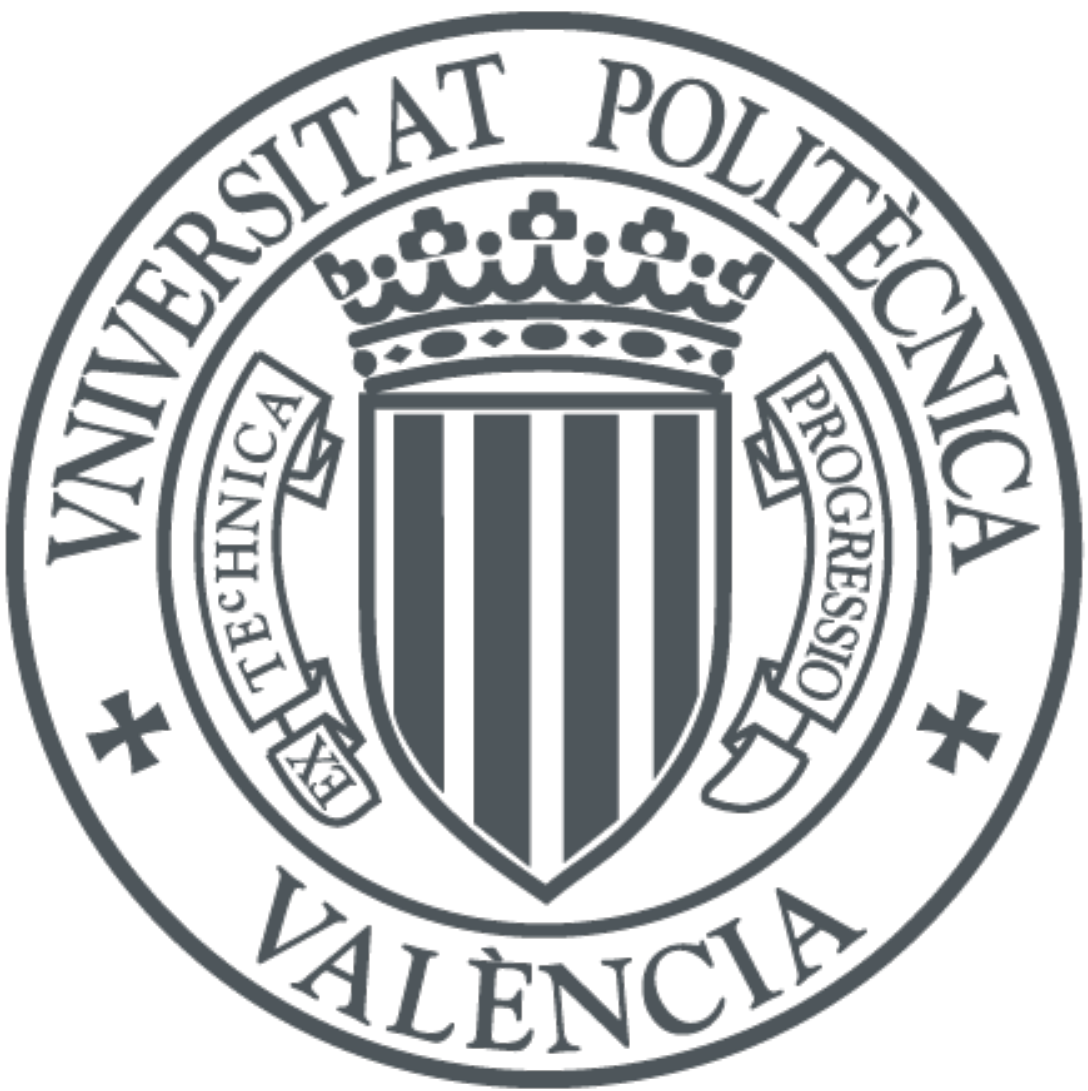

The final publication is available at

http://dx.doi.org/10.1080/09537325.2013.850159

Copyright Taylor \& Francis

Additional Information 


\title{
Research Technology Organisations as leaders of R\&D collaboration with SMES: Role, Barriers and Facilitators
}

\author{
Jose Albors Garrigós and Carlos Rincon \\ Depto. Org. Empresas, Univ. Pol. Valencia \\ 46022 Valencia, Spain
}

\begin{abstract}
Research Technology Organisations or RTOs have attracted academic interest in the last decade due to their role as technology transfer agents and R\&D collaborative leaders for firms, and especially for SMEs. Although their role within the diversity of specialised structures in generating $R \& D$ for industry in National Innovation Systems is recognised, there are scarce publications in relation to their strategies, performance or characteristic, as leaders of $R \& D$ collaboration with SMEs. The aim of this work is to identify the role, barriers and facilitators for RTOs performance as well as to develop a contingency relationship between industry environment, strategy, organisational structure and other factors for successful technology transfer from Technology Organisations to SMEs. This research is based on a field study conducted on fourteen Technology Organisations based in the Valencia region, working with various industry sectors.
\end{abstract}

Keywords: R\&D collaboration; Research Technology Organisations; SMEs; Innovation Strategies; Collaborative innovation networks .

\section{Introduction: Paper Objectives.}

RTOs (Research Technology Organisations) perform a facilitating role in the collaborative efforts of SMEs towards innovation (Aström et al. 2008; Tann et al. 2002). This collaboration contributes to create a competitive advantage for both RTOs and partnering firms (Bititci et al. 2003). However, RTOs still have to face a number of challenges as will be discussed later on.

Usually, the collaboration schemes between RTOs and firms take place through the development of engineering or $\mathrm{R} \& \mathrm{D}$ projects and, in this case, joint project management and communications play a relevant role within such a learning environment (Mas-Verdú 2007).

Moreover, SMEs try to build networks with RTOs for dealing with R\&D, due to the fact that most of these companies do not own real laboratories or R\&D capabilities. Therefore, RTOs could act in different ways within the network, as a hub (Dhanaraj and Parkhe 2006) using its prominence and power to perform a leadership role in pulling together the dispersed resources and capabilities of companies and their networks; or more as a reactive institution. The role of RTOs in orchestrating these networks raises questions regarding their strategy, performance and organisational configuration. 
Most of the academic research on RTOs has focused mainly on external factors such as financing or internal activities (i.e., Barge-Gil and Modrego-Rico 2007) or the changing demand dynamics (Howells, 1999), but it has not extended to organisational

factors or technology transfer, or their impact on final performance. This paper intends to fill that research gap by proposing a construct to identify the different types of strategies that RTOs adopt based on their diverse organisational elements and the technology intensity regime of the firms' environment served by them.

The objectives of this paper are to analyse a specific case of a collaborative scheme, that of the Research Technology Institutes, and, as a first proxy, the particular cases of RTOs in a Spanish region - serving traditional and modern sectors - and their innovation strategies within their role in R\&D collaboration with SMEs. It will analyse as well their approach to conventional RTO strategies.

The research will examine input (independent) and output (dependent) variables that affect the efficiency of the collaborative processes of these RTOs with SMEs. Other context variables such as industry environment have also been taken into account. A construct relating these variables has been proposed as a means of analysing the relationship between the variables.

This paper intends to fill the research gap by proposing a construct to analyse and identify the different types of RTOs based on the different organisational elements and knowledge transfer within the technology regime of the RTO firms' environment. Our research is based on a previous study of outsourced R\&D supported by the Basque Regional Innovation Agency, the denominated R\&D Units (Albors et al. 2010).

This paper is organised as follows: first, a state of the art of RTOs is provided in order to analyse the science and technology policy field context, the RTO strategy body of knowledge as well as the variables which may play a relevant role in the proposed model. Second, the hypotheses are proposed along with the construct which supports them. Third, the research study and methodology are described together with the results of the study. Finally, conclusions are drawn and recommendations for practitioners and policy makers are made.

\section{State of the art: The roles, challenges and strategies of RTOs}

RTOs ${ }^{1}$ have been defined as organisations whose main business is R\&D, with the aim of enhancing the innovative performance of their customers. These organisations are characterised as well by heterogeneity in relation to their mission, ownership, legal and organisational status or output (Leitner 2005). In Europe, these organisations have various outputs ranging from basic research to product development or technical services and engineering (Mas-Verdú 2007). They are a relevant tool for open and global innovation as builders of innovation networks and clusters agents (Vigier 2007).

According to Aström et al. (2008), RTOs' main roles are as mediators, importers, creators and suppliers of knowledge. Additionally, they are providers of infrastructure and independent and partial testing and certification.

RTOs are a fundamental tool for innovation policy and their main role is to address market failures such as appropriability barriers, a well-defined information market, innovation uncertainty and the size of the SME population (Barge-Gil and Modrego-Rico 2008) in their environment. In many countries RTOs carry a substantial 
weight of the R\&D investment and their role may vary according to national context (Aström et al. 2008). They are not substitutable by universities since their services are completely different (Arnold et al. 2007). Research Technology Centres are the first agents to be considered for knowledge generation and transfer (see figure 1) in any Innovation System.

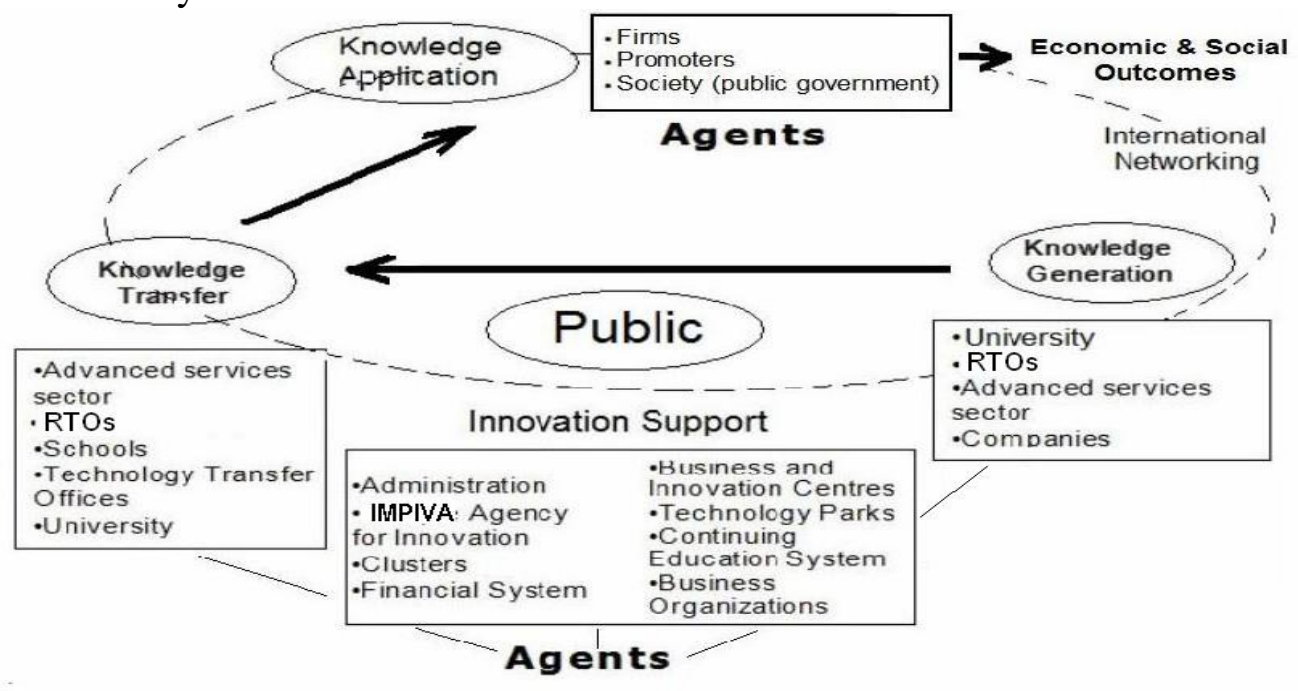

Figure 1. RTO position in the Innovation System.

Oher authors have highlighted the contribution of RTOs as key agents of their territorial innovation system, in compiling and disseminating knowledge since their offer of knowledge-intensive services is relevant to the firm's internationalisation process and supporting connectivity between innovation agents (Barge and Modrego 2008; Martinez-Gomez et al. 2009; Tann et al. 2002). In this respect they play a relevant role in regional development policies by supporting innovation in the SME structure (Vigier 2007)

Additionally, the strengths and weaknesses of the RTOs have been reviewed according to a range of success factors such as continuous monitoring of RTO plans and strategies, the tendency of many organisations to conduct basic research, or engineering activities. It has also been pointed out that most RTOs carry out little advanced research and rarely, if ever, generate major innovations for industry, while playing a role in assisting industry with incremental innovation, problem-solving and the diffusion and absorption of newly-established technologies (Rush et al. 1996).

In this context, the challenges that RTOs currently face should also be highlighted: first they have to compete for research funds in a competitive environment, cope with new research modes where knowledge must be generated within a context of application and, finally, develop research which must be trans-disciplinary (Leitner 2005).

Successful RTOs carry out highly specialised technology tasks such as technology monitoring, development and technology diffusion in close contact with industry. Key areas for continuous review and improvement cover strategy formulation, client monitoring and management, pricing and marketing and human resource management. Therefore, RTOs need a clear strategic vision in order to gain support from both within the RTO and from other important stakeholders in the economy. With a clear, reasoned strategy, RTOs stand a far better chance of contributing to the changing innovation needs of the economy (Arnold et al. 1998; Brockhoff 2003; Leitner 2005). 
This research will present various strategic alternatives followed by RTOs to serve their associated firms, as well as the results. According to Brockhoff (2003), R\&D success can have various meanings. For this author, the results vary for organisations with a higher or lower turnover, which are more or less innovative, compete in dynamic or more stable markets, are most focused on their associated firms or tend to have alternative strategies. All are different success cases and each of the R\&D units will have to rely on a strategy that best fits its needs.

\section{Strategic context and organisational factors influencing innovation and performance of RTOs \\ Strategic context}

Strategic planning has been recognised as an essential tool for RTOs in facing their actual challenges (Arnold et al. 1998; Aström et al. 2008; Rush et al. 1996). For RTOs, it is a key issue to identify what their "business" is and then generate and articulate a strategic vision. This exercise must include basic areas such as strategy formulation, monitoring and management of clients, marketing, developing scientific networking, appropriability policies and human resource management (Arnold et al. 1998; Brockhoff 2003; Rush et al. 1996).

A number of authors (i.e., Saleh and Wang 1993) have analysed how the differences in managerial strategy, organisational structure and organisational climate differentiate between innovative organisations and their performance. For Pitt and Clarke (1999), the management of strategic innovation is "the purposeful orchestration of organizational knowledge development and application". These authors outline various managerial dilemmas associated with this view. Thus, they identify three basic organisational roles in the firm: cultural, process management and development of structures.

There will be environmental factors such as market complexity and stability, competitiveness and context diversity, which will interact contingently with certain variables such as a firm's organisation, age, size or ownership in the selection of innovation strategies (Friedman et al. 2008).

\section{Technological environment and competitiveness. Its impact on RTOS}

The contingent relationships between technology, industry environment and competitiveness have been analysed by various authors as the greatest sources of uncertainty for organisations, and disparities in these areas give rise to differences between organisations (Anderson and Tushman 2001; Zahra and Bogner 1999). Moreover, Dietrich and Shipley (2000) highlight that a competitive environment is the prevalent factor affecting the transfer and adoption of technology. Since competitive environment has been changing and becoming increasingly dynamic, a new technology transfer framework will provide the generic guidelines required for establishing strategic innovation goals, policies and boundaries for technology transfer within a complex and dynamic competitive environment. In this regard, Bozeman (2000) refers to the 'demand environment' as one of the five interrelated factors which influence transfer effectiveness, thus emphasising the importance of an environment that favours technology transfer.

Miller (1987) emphasised a number of variables such as dynamism, hostility and heterogeneity. The more dynamic and hostile the environment, the greater the need for innovation, and, therefore, the more likely the existence of innovative firms. Howells (1999) underlined the relevance of understanding not only the factors affecting the 
demand for SME services but, specially, the changing dynamics of the nature of these services and the way they are supplied by RTOs.

Lumpkin and Dess (2001) report on two dimensions: proactiveness or the way organisation and firms relate to market opportunities, and competitive aggressiveness or how firms react to competitive trends and demands of the marketplace. These authors note that both approaches are related to each other in performance, and differ in the environments in which firms exhibit these approaches to strategy making.

In the case of RTOs (and business links), Bessant (1999) pointed out how targeted approaches were needed in order to facilitate and improve the access of SMEs to Technology Centres due to the diverse technology position of incumbent SMEs. On the other hand, it was outlined how SMEs' technology intensity was an influencing factor in the process of R\&D cooperation (Albors et al. 2010). Mas-Verdú et al. (2009) have analysed the influence of environment in the case of RTO and SME collaboration.

\section{RTOs and organisational factors: Contingent approach}

The RTOs' decisions about service supply and knowledge generation are part of their strategic approach and organisational design to allow compatibility (Modrego-Rico and Barge-Gil 2005). Subsequently, RTOs must optimise their social learning cycle and develop organisational competencies aligned with the scientific and technical knowledge progression required in the organisation (Pitt and Clarke 1999).

Human resources development and management, it has been argued, constitute a benchmarking indicator for excellent performing RTOs (Nath and Mrinalini 2000; Rush et al. 1996). These include professional career planning, training and skill development compensation policies, network training, etc.

In a seminal work, Burns and Stalker (1961) defined the relationship between "mechanistic" and "organic" organisational systems - variables to the rate of "environmental" change. The latter referred to the technology basis of industry and to the uncertainty of the market situation. Organic structures are more flexible and adaptable to changing environment conditions, while mechanistic structures are more rigid and correspond to more stable and mature industries. Furthermore, other organisational theorists, Jassawalla and Sashittal (1998), define two alternative structures: 'pronoia' and 'paranoia', relating to organic and mechanistic systems respectively. They note that "paranoia" environments tend to slow down technology transfer; in contrast, "pronoic" organisations activate the process. Pronoia is defined as a managerial/organisational condition of health and vibrancy and the projection of interpersonal, group and organisational cohesiveness that is ascribed to the general, veritable effectiveness of others. Consequently, a major objective of an organisation's strategy-making in relation to R\&D activities should be to attain congruence or 'fit' among key variables such as environment, organisational structure and strategy in order to achieve optimal performance (Davies and Walters 2004; Grandy and Mills 2004).

In this case, and with the exception of two authors (Deutsch et al. 2009 and Rush et al 1996), who pointed out the relationship between RTOs strategies and organisational variables, we have not found any literature analysing the specific relationships of RTOs' organisational structure and their R\&D strategies, except in the case of the R\&D units mentioned (Albors et al. 2010). This is another of the research gaps the paper aims to fill.

\section{Relationships of the centre with the served firms and other firms and institutes}

The collaboration of RTOs with their customers and other firms, and the related networks established have been emphasised as best practices by various authors 
(Mirinilani and Nath 2008; Mazzoleni and Nelson 2007; Nath and Mrinilani 2000; Zubiaurre et al. 2004). Rush et al. (1996) specify that close industrial links form part of the success factors of RTOs and contribute closely to their market responsiveness. These authors also draw attention to the construction of close links with universities and other RTOs as tools for building business intelligence. Moreover, as has already been mentioned, Castro and Mota (2009) consider RTOs' potential agents of a local firm's collaborative innovation network.

When some researchers (Modrego-Rico and Barge-Gil 2005) propose indicators to measure RTO performance these include, among other factors, a relational dimension based on closeness to scientific and entrepreneurial environment as well as collaboration with scientific environment.

Specifically, the services supplied by technological centres with the purpose of improving regional innovative potential have been examined by García-Quevedo and Mas-Verdú (2008). However, according to these authors, demand for services increases with the size of the client company. Spatial proximity between the client company and the supplier of the services also seems to be a relevant factor. In a study of the five ITS systems in the North of Europe, Astrom et al. (2008) show that more than $60 \%$ of clients are small companies. Molina and Mas-Verdú (2008) have analysed RTO cooperation arrangements and innovation performance. In contrast with existing studies, we have provided empirical evidence of the impact of external factors on individual firms.

\section{RTO performance and output indicators}

As regards RTOs, there is lack of literature related to performance indicators. ModregoRico and Barge-Gil (2005) suggest the following indicators: self-financing ratio as a measure of the RTO's capacity for obtaining funds in competition with other agents; relational dimension as the capacity of RTOs to interact with other agents in their environment; organisational dimension (which includes factors related to learning practices, strategic planning, human resources management, $R \& D$ projects management and marketing management); and, finally, output variables related to the impact of the centre represented by new products and processes developed for their clients. ModregoRico and Barge-Gil classified these indicators into three groups of variables: service supply, output and explicative. A more focused approach has tried to identify benefits and competitive advantages gained by the incumbents of a collaborative effort (Camarinha-Matos 2007), and this is the research direction the present paper has followed.

Other authors have proposed knowledge transfer as a benchmarking indicator, including knowledge dissemination to be measured by feedback from client companies, and measuring knowledge transfer items as an alternative (Nath and Mrinalini 2000). Garcia Quevedo and Mas-Verdú (2008) have outlined the difficulties of RTOs to carry out R\&D with small firms.

A more straight forward approach based on intangible assets has been proposed by the Austrian Research Centre association (ARC). This organisation proposed four types of indicators:

(1) Intellectual capital indicators such as scientific staff, employee rotation, training programmes, percentage of women, professional career planning, etc.

(2) Process indicators such a national, international or funded projects, percentage of independent research, etc.

(3) Results including financial, research, or industry oriented. 
(4) Society oriented results such as the RTO web impact and involvement in scientific societies (Leitner 2005).

Finally, a practical definition and measurement of innovation has been proposed by Arundel and Hollanders (2008) and used by the European Commission. The scoreboard identifies six types of indicators:

- Innovation diversity

- Innovation-friendly markets

- knowledge flows

- Innovation investment

- Innovation governance, of which some are applicable to the case of RTOs (i.e., number of patents, new activities, new products or processes, new spin off firms, scientific publications per person, etc.).

In relation to RTO performance indicators and following the mentioned approach of Camarinha-Matos (2007), a positive relationship between turnover or sales figures and $R \& D$ intensity has been underlined (Aström et al. 2008). These authors consider, as well, the relevance of turnover from performance contracts with private firms and its relevance as a self-financing indicator (Modrego-Rico and Barge-Gil 2005). However, other authors discuss the difficulty of conciliating project contract sales with innovation performance due to the lack of research freedom associated with these types of contracts (Arnold et al 1998; Nath and Mrinalini 2000).

Again, academic literature has not discussed the relationship between RTO performance and the previous reviewed factors (technology intensity regime, organisational structure, relational activities, innovation strategy and SME orientation). Thus, the holistic construct proposed by the paper analysing this relationship will be a contribution to fill the mentioned research gap.

\section{Hypotheses and performance model}

The theoretical review appears to show that the influence and role of environment in the crafting of the organisation's innovation strategy has been widely recognised. Consequently, the research hypotheses are formulated below in relation to RTOs' role in the R\&D collaborative network of SMEs. It should be mentioned that the different goals of the R\&D units in terms of their final results were evident in the interviews; while some were more concerned with innovation excellence, others were more focused on economic performance or self sustainability. This reinforces the idea that RTOs' strategy depends on the role they want to play in the SME collaborative innovation network. This observation underpins the first hypothesis:

\section{Table 1. Hypothesis 1.}

\begin{tabular}{|l|l|}
\hline Hypothesis 1 & References \\
\hline $\begin{array}{l}\text { The innovation strategy } \\
\text { of the RTOs is }\end{array}$ & Anderson and Tushman 2001; Bozeman 2000; Burns and Stalker 1961; \\
Dependent on served & Gopalakrishnan 1998; Friedman et al. 2008; Grandy and Mills 2004; \\
industry environment, & Jassawalla and Sahsital 2002; Jassawalla and Sahsital 1998; Lumpkin and \\
$\begin{array}{l}\text { RTO organisational } \\
\text { structure, its relational } \\
\text { skills and its SME }\end{array}$ & Dess 2001; Modrego-Rico and Barge-Gil 2005; Mrinalini and Nath 2008; \\
focus. & Wang 1993; Stock and Tatikonda 2000; Walker and Ellis 2000; Zahra dn \\
\hline
\end{tabular}

As was considered earlier, structure and personnel policies have a significant role in the innovation intensity level within the organisational approach as a result of the challenges assumed by the RTO within the collaborative innovation network. Accordingly, the following hypothesis is proposed: 
Table 2. Hypothesis 2

\begin{tabular}{|l|l|}
\hline Hypothesis 2 & References \\
\hline $\begin{array}{l}\text { The more organic the } \\
\text { organisational structure of } \\
\text { the R\&D Unit, the higher its } \\
\text { innovation output. }\end{array}$ & $\begin{array}{l}\text { Modrego-Rico and Barge-Gil 2005; Pitt and Clarke 1999; Rush et al. } \\
\text { 1996; Stock \& Tatikonda 2000. }\end{array}$ \\
\hline
\end{tabular}

The theoretical review concluded that in terms of the RTO financial performance indicators, some authors precluded a positive relationship between turnover or sales figures and R\&D intensity as well as innovation output, while others expressed certain doubts. This observation emphasised that RTOs' commitment to client companies' needs (as facilitators of their R\&D) should have an effect on their financial performance. Thus, the following hypothesis can be proposed:

Table 3. Hypothesis 3.

\begin{tabular}{|l|l|}
\hline Hypothesis 3 & References \\
\hline $\begin{array}{l}\text { Considering the output } \\
\text { results, the unit innovation }\end{array}$ & Arnold et al. 1998; Aström et al. 2008; Leitner 2005; Modrego-Rico \\
performance is related to its & \\
financial performance-Gil 2005; Nath and Mrinalini 2000. \\
indicators.
\end{tabular}

In order to understand the relationship between the variables, Figure 2 shows the construct scheme which represents the model to be tested. Some authors (i.e., Leitner 2005; Nath and Mrinalini 2000) tend to consider RTO complex models with a larger number of indicators of performance (i.e., relational skills), which we view as really explicative factors. In our case we adapt the model proposed by Modrego-Rico and Barge Gil (2005), which considers outputs such as self-financing (turnover) and added value (innovation output) for simplicity. Variables such as environment, innovation strategy, relational activities, absorptive capacity, project management routines or organisational structure are interpreted as independent variables although their interdependence will also be analysed. The impact on the environment should be left for a second phase of our research programme.

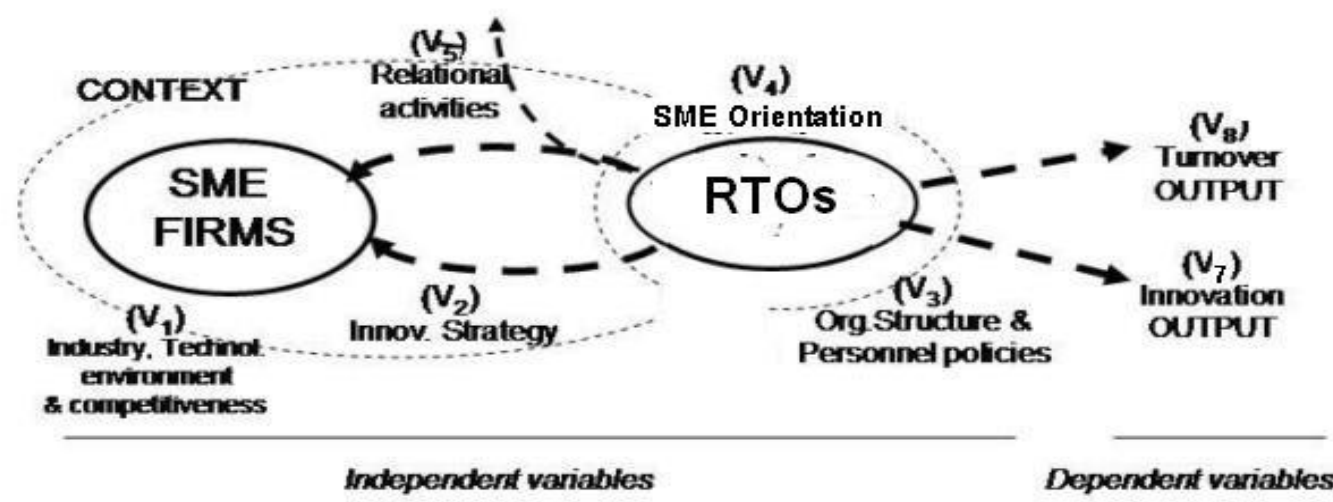

Figure 2. Construct used to analyse R\&D units. 


\section{Research methodology and study: Results.}

\section{RTOs in the region of Valencia}

The promotion of RTOs by the Valencia Regional Government was initiated during the mid 1980s and is presently comprised of 14 units. Their primary mission was defined as "serving the local industry (basically SMEs) in the medium and long term, as well as developing and valuing their technological capabilities" (Redit 2009). Impiva, a Valencian regional government agency, founded the technology institutes networks to serve established industries, and local business innovation centres to back up new projects, following the examples of Emilia Romagna (Italy), Baden-Württemberg (Germany) and Denmark. One setback, however, is the lack of trust between entrepreneurs in these regions. Some institutes are sector focused, for example, AIJU, the institute of toys located in Ibi, INESCOOP, the institute of shoe manufacturing located in Elche, AIMME the institute of furniture, or AIMME the institute of metal mechanic industry located in Valencia. Other institutes were established later using a horizontal approach with a multidisciplinary technology focus such as AIDO, the Optical Technology Institute or ITI, the Information Technology Institute, both based in Valencia (Holmström 2006). Actually, the Valencia region RTOs total investment in $R \& D$ accounts to $25 \%$ of the total investment in R\&D of the region (Redit 2009).

\section{Research methodology}

The research work was based on a questionnaire filled in during personal interviews carried out with managers of 14 RTOs active in the Valencia Region ${ }^{2}(100 \%$ representative sample). Each interview lasted between two and three hours. In order to obtain the most reliable results possible, the interviewers ensured that the questions were properly understood and fully completed.

Taking into account the research objectives as well as the number and characteristics of the R\&D organisations, the methodology was based on a questionnaire comprising some 50 questions covering eight areas of the R\&D unit operation. Although the sample was limited in size it included $100 \%$ of the RTO population in the region and from the point of view of the representativeness it was perfectly acceptable. However, the sample size limits the extension of a multivariate analysis and with the objective of simplifying the number of variables and adapting them to the selected construct; six independent variables were selected for this article from the replies obtained. The key variables utilised for the analysis were as follows:

- Technological Environment and Market Competitiveness $\left(\mathrm{V}_{1}\right)$

- Innovation Strategy $\left(\mathrm{V}_{2}\right)$

- Organisational structure and personnel policies $\left(\mathrm{V}_{3}\right)$

- Market orientation towards SMEs $\left(\mathrm{V}_{4}\right)$

- Relationship of the R\&D unit with served firms, universities and other RTOs $\left(\mathrm{V}_{5}\right)$

- Innovation Performance $\left(\mathrm{V}_{6}\right)$

- Turnover per employee $\left(\mathrm{V}_{7}\right)$. They were measured on a 5- point Likert Scale. 
For the output variables, turnover per employee without public support (as a measure of self sustainability) and innovation intensity were selected. Innovation intensity was measured by the number of patents, new activities, new products, new spin off firms and scientific publications per RTO employee in the last three years. Table 4 shows the variables built and how these were constructed from the survey questionnaire.

The final values assigned to the variables were 1 to 5 on a Likert scale, based on a recalculation related to the average values of each variable thus obtaining standardised factors. 
Table 4. Construct variables and their meaning.

\begin{tabular}{|c|c|c|}
\hline & Variable & Related Questions (items) \\
\hline $\mathrm{V}_{1}$ & $\begin{array}{l}\text { Technological Environment and Market } \\
\text { Competitiveness }\end{array}$ & $\begin{array}{l}\text { Technology uncertainty, market } \\
\text { competitiveness, technology life } \\
\text { cycle (Turbulent versus Statics). }\end{array}$ \\
\hline $\mathrm{V}_{2}$ & Innovation Strategy & $\begin{array}{l}\text { Motivation for the Unit } \\
\text { establishment, R\&D activity, risk } \\
\text { assumption policies, research } \\
\text { freedom, pioneering, links with third } \\
\text { party non associated firms (Proactive } \\
\text { versus Reactive). }\end{array}$ \\
\hline $\mathrm{V}_{3}$ & Organisation Structure and Personnel Policies & $\begin{array}{l}\text { Hierarchy levels, organisation } \\
\text { structure, staff stability, working } \\
\text { groups, decision-making, personnel } \\
\text { selection criteria, professional } \\
\text { careers, salary policies (Mechanical } \\
\text { versus organic). }\end{array}$ \\
\hline $\mathrm{V}_{4}$ & Market orientation towards SMEs & Percentage of SME customers. \\
\hline $\mathrm{V}_{5}$ & $\begin{array}{l}\text { Relationship of the centre with the served firms } \\
\text { and other RTOs and universities }\end{array}$ & Level of Relationships. \\
\hline $\mathrm{V}_{6}$ & Innovation Performance & $\begin{array}{l}\text { Patents, licenses, spin offs, } \\
\text { publications and new products, or } \\
\text { processes. }\end{array}$ \\
\hline $\mathrm{V}_{7}$ & Unit Performance TURNOVER & $\begin{array}{l}\text { Turnover per employee without } \\
\text { public support (euros } \times 10^{3} \text { ). Values } 1 \\
\text { to } 5 \text { corrected thorough mean values. }\end{array}$ \\
\hline
\end{tabular}

\section{Results}

Table 5 shows the results of the interpretation of the questionnaires. It must be pointed out that RTOs numbers 4, 5, 6, 7, 10,11, 12 and 13 are vertical or sectorally focused. It can be observed that, in principle, variables $\left(\mathrm{V}_{1}\right)$ and $\left(\mathrm{V}_{2}\right), \mathrm{V} 1$ and $\left(\mathrm{V}_{3}\right)$ and $\left(\mathrm{V}_{1}\right)$ and $\left(\mathrm{V}_{5}\right)$ are bilaterally related.

Table 5. Variables values according to the replies of the questionnaire

\begin{tabular}{|l|l|l|l|l|l|l|l|}
\hline RTO \# & V1 & V2 & V3 & V4 & V5 & V6 & V7 \\
\hline 1 & 4,85 & 4,2 & 3,95 & 3,9 & 4,01 & 4,22 & 5 \\
\hline 2 & 4,55 & 4,25 & 4,05 & 3,5 & 4,19 & 4,55 & 2,3 \\
\hline 3 & 2,1 & 2,2 & 1,85 & 4,2 & 1,85 & 1,70 & 2 \\
\hline 4 & 2,32 & 2,1 & 1,99 & 4,3 & 2,05 & 2,50 & 1,5 \\
\hline 5 & 3,52 & 3,65 & 2,95 & 4,1 & 3,95 & 3,25 & 4,5 \\
\hline 6 & 4,15 & 3,75 & 3,85 & 3,2 & 4,65 & 4,75 & 2,8 \\
\hline 7 & 3,69 & 3,05 & 2,95 & 3,5 & 2,85 & 3,25 & 3,5 \\
\hline 8 & 3,12 & 2,99 & 2,8 & 2,6 & 2,5 & 2,95 & 1 \\
\hline 9 & 4,92 & 3,99 & 3,85 & 3,5 & 3,85 & 4,10 & 3,2 \\
\hline 10 & 3,02 & 2,89 & 1,75 & 4,15 & 2,32 & 2,32 & 2,2 \\
\hline 11 & 2,99 & 2,85 & 1,92 & 4,05 & 2,89 & 2,65 & 2,9 \\
\hline 12 & 3,15 & 2,75 & 2,2 & 3,75 & 2,96 & 3,15 & 4,1 \\
\hline 13 & 3,02 & 2,83 & 2,9 & 3,99 & 3,51 & 3,05 & 4,1 \\
\hline 14 & 3,25 & 2,84 & 2,4 & 3,6 & 3,05 & 2,65 & 3 \\
\hline
\end{tabular}

Table 6 shows the bivariate correlations between all variables. As mentioned, the sample is $100 \%$ representative of the RTO population in the region, but due to its small size (below $\mathrm{N}=25$ ), the correlation coefficients must be interpreted with caution (Tompkins 1992), especially in the case of an excess of outlier cases. However, a sample size of 15 with an acceptable significant level $(\alpha)$ of 0,05 encompass an absolute error of 0,58 . 
In those cases of acceptable correlation coefficient, table 6 shows a positive relationship between the RTO strategy $\left(\mathrm{V}_{1}\right)$ and its innovation strategy $\left(\mathrm{V}_{2}\right)$, its $\left(\mathrm{V}_{5}\right)$ organisational structure $\left(\mathrm{V}_{3}\right)$, their relationship level with other research centres and their innovative performance $\left(\mathrm{V}_{6}\right)$. The RTO innovation strategy $\left(\mathrm{V}_{2}\right)$ has a positive relationship with the organisational structure $\left(\mathrm{V}_{3}\right)$, their relationship level with other research centres $\left(\mathrm{V}_{5}\right)$ and their innovative performance $\left(\mathrm{V}_{6}\right)$. The organisational structure $\left(\mathrm{V}_{3}\right)$ of the RTOs is positively related with their relationship level with other research centres $\left(\mathrm{V}_{5}\right)$ and their innovative performance $\left(\mathrm{V}_{6}\right)$. Finally, the RTO relationship level with other research centres $\left(\mathrm{V}_{5}\right)$ is positively related with their innovative performance $\left(\mathrm{V}_{6}\right)$.

Although the table shows certain correlation coefficients between the SME focus of the RTOs $\left(\mathrm{V}_{4}\right)$ and other variables, generally of negative signs, an excessive number of outliers impede drawing clear conclusions.

No significant correlation was found between the RTOs turnover figures $\left(\mathrm{V}_{7}\right)$ and other variables.

It can be concluded from the previous results that those RTOs with a more turbulent and changing industry environment and a stronger competitive market, mainly due to high technology rotation, follow more proactive innovative strategies, while RTOs serving mature sectors in medium to low tech industries show more reactive innovative strategies when supporting the R\&D collaboration with their customer firms. Similarly, those RTOs serving firms competing in more turbulent environments show organisational structures organically oriented and with a "pronioa" profile as advanced by Burrns and Stalker (1961) as well as Jassawalla and Sashittal (1998). In similar terms, but opposing conclusions, we could refer to those RTOs serving firms in more mature and stable environments. As regards the relational skills of the RTOs, those showing higher values of relationships tend to be immersed in more turbulent and changing industries, which could be interpreted as their need for a higher level of partnering and knowledge sharing.

In relation to the innovative performance of RTOS, it seems to benefit from a more competitive and technology active environment, proactive strategies, organic structures and a higher level of relationships.

Finally, it is difficult to interpret the relationships of the SME focus of the RTOs with other variables from the analysed data. Our interviews show that SME relationship with RTOs was difficult, especially in those firms of smaller size in innovative projects that are R\&D led. A different case was the relationship of RTOS with SMEs in other services such as analysis, engineering, quality certificates, etc. It seems that RTOs identify the lack of innovation culture in SMEs as a relevant barrier. Some of them try to involve SMEs in cooperative innovation programmes with the support of Regional and National programmes. This could be interpreted as the need for reactive strategies (short term demands) and classical organisational approaches to deal with small size firms' approach to $R \& D$ collaboration. The type of services required with a low $R \& D$ content hinder as well the outcome of innovative outputs. 
Table 6. Correlations between all variables

\begin{tabular}{|l|c|c|c|c|c|c|c|}
\hline Kendall Tau_b & V1 & V2 & V3 & V4 & V5 & V6 & V7 \\
\hline V1 & & & & & & & \\
\hline V2 &, $707(* *)$ & & & & & & \\
\hline V3 &, $715(* *)$ &, $700(* *)$ & & & & & \\
\hline V4 &,$- 506(* \S)$ &,$- 402(* \S)$ &,$- 452(* \S)$ & & & & \\
\hline V5 &, $619(* *)$ &, $538(* *)$ &, $700(* *)$ & & & & \\
\hline V6 &, $715(* *)$ &, $633(* *)$ &, $831(* *)$ &,$- 520(* \S)$ &, $767(* *)$ & & \\
\hline V7 & & & & &, $420(* \S)$ & & \\
\hline $\begin{array}{r}\text { Kendall Tau_b } \\
* * p<0,01 \\
*\end{array}<<0,05$ & V1 & V2 & V3 & V4 & V5 & V6 & V7 \\
\hline
\end{tabular}

Figure 3 shows the dispersion plot of the variables with the Environment variable represented in the $\mathrm{Y}$ axis. This graph shows more visually the relationships between those variables.

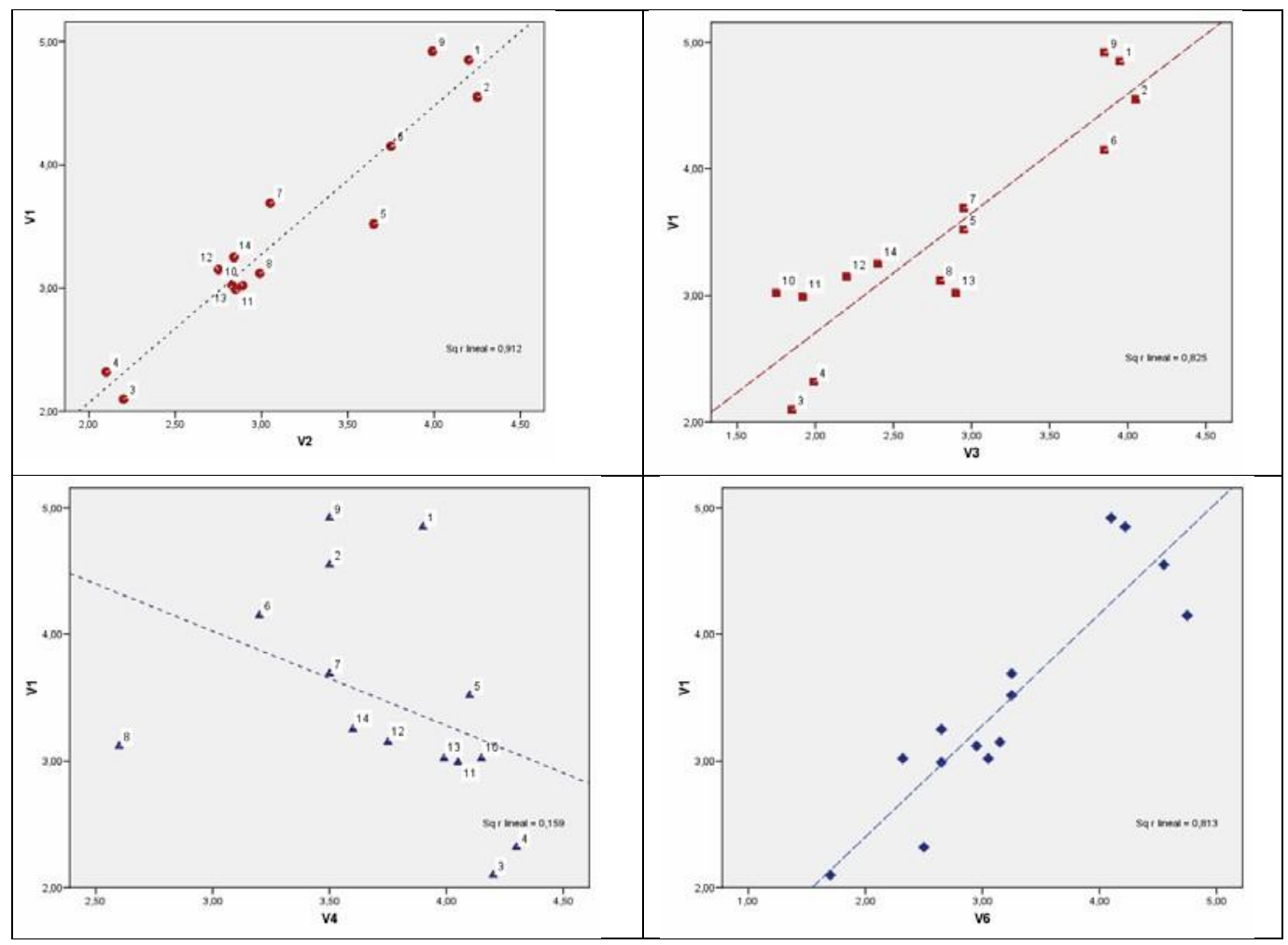

Figure 3. Dispersion Graphic Plot of variables relationship results.

\section{Discussion}

As regards the hypotheses proposed, the conclusions drawn from the data analysed are summarised below.

Firstly, the proposed model supports empirically a relationship between technology and industry environment, strategy and organisational structure following the Burns and Stalker (1961) premise, which holds that strategy-making in RTOs should look for congruency among key variables such as environment, structure and strategy in order to achieve optimal performance. Those RTOs leading firms' collaborative R\&D in a more turbulent and competitive environment (RTO number 1, 2, 5, 6 and 9) possess 
a higher level of organic structure and follow a more proactive innovation strategy. Moreover, their relationship skills are higher taking advantage of a more dense relationship network with other international RTOs, universities and other agents. However, they are not more oriented towards a SME segment than others. We can conclude then that hypothesis 1 can be validated partially.

Secondly, considering the organisational structure of the RTOs, this variable seems to be associated as well with the relationships variable and the innovation performance variable. Thus, hypothesis 2 is completely validated indicating that RTOs follow the Burns and Stalker model in terms of the innovation performance, relating to the effect of two alternative structures: organic and mechanistic systems.

With regard to the economic performance (turnover) this variable does not seem to be related to the innovation performance. Those RTOs with a higher turnover per employee (RTO number 1, 5, 11, 12, 14, 9 and 7) show varied values of innovation performance which do not allow us to infer any conclusions. It has also been noted that engineering contracts, competitive research projects or technical services do not imply innovation results but contribute to a higher RTO performance. It cannot be concluded a negative relationship as in the case of focused or specialised RTOs (see Albors et al. 2010).

\section{Summary and Final Conclusions}

The main objective of this paper was to analyse performance models followed by RTOs - serving traditional and modern sectors - and their innovation strategies related to their role in the R\&D collaboration approach of SMEs. The aim was to examine as well their approach to conventional RTO strategies when dealing with companies' collaborative innovation. The research considered input and output dependent variables which may affect their efficiency. A relevant context variable - their industry environment - was also taken into account as a moderating factor.

The literature review showed how various authors have analysed diverse aspects of RTOs as facilitators of the R\&D collaborative networks of companies. The relevance of RTOs strategies and the need to outline clearly their mission and vision have been also emphasised as a means of fulfilling their role as leaders for R\&D collaboration. Various authors have also analysed RTO organisational factors and their relationships with their challenges. The role of RTOs in the technology transfer tasks were also discussed as well as its service to SMEs. Finally, a relevant area of research was the discussion of various indicators utilised to measure its performance. Some authors focused on performance indicators, which were viewed as strategic tools as in the case of the relationship connections of RTOs.

It could be concluded that the actual body of knowledge on RTOs' role in R\&D collaboration with companies lacks a certain connection between the various themes or areas covered in relation to RTOs. This has been the aim of this paper, which proposes a model connecting the industry or served environment by RTOs with their strategy, their organisational elements and their performance as well as their fitness to provide technological services to the SME regional population in their region.

The paper analysed context variables such as technology environment and market competitiveness, and organisational variables such as innovation strategy, structure and personnel policies, relational policies and RTO SME focus. Both types of variables affect the efficiency of RTOs measured by their innovation output and their turnover per employee.

According to the proposed construct, the model shows that different R\&D collaborative approaches will require different strategies in order to achieve excellent performance (as suggested by Arnold et al. 1998 or Cesaroni et al. 2004). It appears that 
organisational policies are influenced by strategy and environment, and hence the more organic RTOs are more open to other research partners, firms and RTOs and posses a higher technology level and innovation performance. However, it seems that mechanistic R\&D units pay greater attention to engineering because their technology rotation ratio is lower, and they are more focused on turnover results. It is interesting to observe how this construct follows Burns and Stalker's (1961) as well as Jassawalla and Sashittal's (1998) propositions. Nevertheless, the authors would emphasise that turnover is not a clear and independent objective for RTOs but only a means for sustainability (Arnold et al. 2007).

This situation opens a paradigm selection for those RTOs working in more traditional industry environments such as furniture, textile, tile ceramics, etc. These have to balance their strategy between traditional certification and consultancy services and a higher R\&D and innovation focus, while supporting a sustainable financial status. A further limitation for these RTOs is the SME market focus due to its reactive approach and their lower innovative culture.

The limitations of this paper result basically from the size of the sample which, although $100 \%$ representative of the population, does not allow a powerful regression analysis or more complex regression models. It must be taken into account as well that the study has concentrated on the RTO population of a single region, the East of Spain. On the other hand, the research will require a full analysis from the served firm's perspectives, which should shed more light on the interactions between RTO and their customers. ${ }^{3}$ Finally, the contributions of this study must be interpreted with caution, since in spite of a relatively long-term perspective, the focus has been on the Valencia Region context, which may have certain characteristics - a weak mature industry leaning towards traditional sectors and composed heavily of small firms. The ongoing research project covers Spain and future papers will compare and discuss the results of the analysis of RTOs serving various regions.

1. We have adopted this term in order to generalise its inception.

2. This research project is currently examining RTOs based in the Valencia region and in the Basque Country, in order to compare the role of industrial environment and regional policies.

3. The object of our following research.

\section{Referentes}

Albors-Garrigos, J., Zabaleta, N. \& Ganzarain, J. 2010. New R\&D management paradigms: rethinking research and technology organizations strategies in regions. $R \& D$ Management, 40, 435-454.

Anderson, P. and Tushman, M.L. 2001. Organizational Environments and Industry Exit: the Effects of Uncertainty, Munificence and Complexity. Industrial and Corporate Change, 10, (3), 675-711.

Arnold, E.; Rush, H.; Bessant, J. and Hobday, M. 1998. Strategic Planning in Research and Technology Institutes. R\&D Management, vol. 28, no.2, pp. 89-100. 
Arnold, E., Brown, N., Eriksson, A., Jansson, T., Muscio, A. Nählinder, J., Zaman, N. 2007. The Role of Industrial Research Institutes in the National Innovation System. Vinnova.

Arundel, A. and Hollanders, H. "Innovation Scoreboards: Indicators and Policy Use", in C. Nauwelaers and R. Wintjes (eds.). Innovation Policy in Europe, Edward Elgar: Cheltenham, February 2008

Aström, T., Eriksson, M.L., Arnold, E. 2008. International Comparison of Five Institute Systems. Forsknings-og Innovationsstyrelsen. Copenhagen.

Barge-Gil, A.; Modrego-Rico, A. 2007. Los centros tecnológicos como instrumentos de intervención pública. In Vence, X. editor Crecimiento y Políticas De Innovación : Nuevas Tendencias y Experiencias Comparadas. Ed. Pirámide, Madrid. 241-271.

Barge-Gil, A., Modrego-Rico, A., 2008 Are technology institutes a satisfactory tool for public intervention in the area of technology? A neoclassical and evolutionary evaluation. Environment and Planning C. Government and Policy, 26, 808-823.

Bessant, J. 1999. The rise and fall of 'Supernet': a case study of technology transfer policy for smaller firms. Research Policy, 28, 601-614.

Bozeman, B. 2000. Technology Transfer and public Policy: a review of research and theory. Research Policy, 29, 627-655.

Burns, T. and Stalker, G. M. 1961. The Management of Innovation, Third edn. Oxford University Press.

Brockhoff, K. 2003. Exploring Strategic R\&D Success Factors, Technology Analysis \& Strategic Management, 15 (3), 333-348.

Castro, L.M., Mota, J. 2009. Technological Centers as a Negotiated Context to Combine Technological Capabilities. Group Decis Negot, 18, 467-482.

Camarinha-Matos, L. 2007. Special Issue: Modeling approaches and frameworks for collaborative networks. Journal of intelligent manufacturing, 18 (5), 527.

Damanpour, F. and Gopalakrishnan, S. 1998. Theories of organizational structure and innovation adoption: the role of environmental change. Journal of Engineering and Technology Management, 1-24.

Davies, H. and Walters, P. 2004. Emergent patterns of strategy, environment and performance in a transition economy. Strategic Management Journal, 25, 347-67.

Deutsch, C., Leclerc, J.C., Meneghini, C. 2009. Successfully aligning the organizational structure of a R\&D centre to the reality of today's environment, Proceedings ISPIM and $R \& D$ management Conference, Vienna, 2009.

Dhanaraj, C. and Parkhe, A., 2006. Orchestrating innovation networks. Academy of Management Review, 31 (3), 659-669.

Dietrich, G. B. and Shipley, M. F. 2000. Technology Transfer in a complex environment: Exploring key relationships, in 2000 IEEE International Engineering Management Conference.

Friedman, R.S., Roberts, D.M., Linton, J.D. 2008. Principle Concepts of Technology and Innovation Management: Critical Research Models. IGI Publishing Hershey, PA García-Quevedo J.; and Mas-Verdú, F. 2008. Does only size matter in the use of knowledge intensive services? Small Business Economics, 31, 137-146.

Grandy, G. and Mills, A. J. 2004. Strategy as Simulacra? A Radical Reflexive Look at the Discipline and Practice of Strategy. Journal of Management Studies, 41, 1153-70.

Holmström, M. 2006. Globalisation and good work: IMPIVA, a spanish project to regenerate industrial districts. Tijdschrift voor economische en sociale geografie, 97, (5), 491-502.

Howells, J. (1999) Research and Technology Outsourcing, Technology Analysis \& Strategic Management, Vol. 11, 1, pp.17-29. 
Jassawalla, A. R. and Sashittal, H. C. 1998. Accelerating Technology Transfer: thinking about organizational pronoia. Journal of Engineering and Technology Management, 15, 153-177.

Jassowalla A.R., and Sashittal, H.C., 2002. Cultures that support product innovation processes. Academy af Management Executive, 16 (3), 42-65.

Leitner, K.H. 2005. Managing and reporting intangible assets in RTOs. $R \& D$ Management, 35, (2), 125-136.

Lumpkin, G.T. and Dess, G.G. 2001. Linking two dimensions of entrepreneurial orientation to firm performance: The moderating role of environment and industry life cycle. Journal of Business Venturing, 16 (5), 429-451.

Mas-Verdú, F. 2008. Does only size matter in the use of knowledge intensive services? Small Business economic, 31, 137 -146.

Mas-Verdú, F. Baviera-Puig, A. and Martinez-Gomez, V. 2009. Entrepreneurship policy and targets: the case of a low absorptive capacity region. International Entrepreneurship and Management Journal, 5 (3), 243-258.

Modrego-Rico. A. and Barge-Gil, A, Nuñez-Sanchez, R. 2005. Developing indicators to measure technology institutes performance. Research Evaluation, 14, (2), 177-184.

Molina, F.J. and Mas-Verdú, F. 2008. Intended Ties with Local Institutions as a Factor in Innovation: An Application to Spanish Manufacturing Firms. European planning studies, 16 (6), 25-37.

Martínez-Gómez, V., Baviera Puig, A., Mas-Verdú, F. 2009. Innovation policy, services and internationalization: the role of Technology Centres. The Services industries Journal, 1(14), 2-19.

Mazzoleni, R. and Nelson, R.R. 2007. Public research institutions and economic catchup. Research Policy, 36, 1512-1528.

Miller, D. 1987. The Structural and Environmental Correlates of Business Strategy.

Strategic Management Journal, 8, 55-76.

Molina Morales, F.J. and Mas Verdu, F. 2008. Intended Ties with Local Institutions as a

Factor in Innovation: An Application to Spanish Manufacturing Firms. European

planning studies, 16 (6), 25-37.

Mrinalini, N., and Nath, P.. 2008. Knowledge Management in Research and Technology Organizations in a Globalized Era Perspectives. Global Development and Technology, 7 (1), 37-54.

Nath, P. and Mrinalini, N., 2000. Benchmarking the best practices of non corporate R\&D organizations. Benchmarking, 7, (2), 86-97.

Pitt, M. and Clarke, K. 1999. Competing on Competence: A Knowledge Perspective on the Management of Strategic Innovation. Technology Analysis \& Strategic Management, 11 (3), 301-316.

Rush, H.; Arnold, E.; Bessant, J. and Murray, R. 1996. Technology Institutes: Strategies for best practice. Thomson Learning.

Saleh, S.D. and Wang, C.K. 1993. The management of innovation: strategy, structure, and organizational climate. IEEE Transactions on Engineering Management, 40 (1), 1421.

Stock, G. N. and Tatikonda, M. V. 2000. A typology of project-level Technology Transfer processes. Journal of Operations Management, 18, 719-737.

Tann, J., Platts, A.E., Stein, J. 2002. The roles of independent RTOs in the U.K. Technology Transfer mechanisms to SMEs. Technology Analysis \& Strategic Management, 14 (2), 241-249.

Tompkins, C.A. 1992. Using and Interpreting Linear Regression and Correlation Analyses. Clinical Aphasiology, 19, 35-45. 
Vigier, P. 2007. Towards a citizen-driven innovation in Europe: A governance approach for a European innovation agenda. Innovation, 20 (3), 191 -202.

Walker, A. and Ellis, H. 2000. Technology Transfer: Strategy, Management, Process and inhibiting factors. International Journal of Innovation Management, 4 (1), 97-122. Zahra, S.A. and Bogner, W. 1999. Technology strategy and software new ventures performance: exploring the moderating effect of the competitive environment. Journal of Business Venturing, 15, 135-173.

Zubiaurre, A., Astoreca, M., Guibert. J.M., Zabala, K., 2004. Collaboration relationships between firms and TCs in the Basque Country. Pattern of Innovation matters, Proceedings 13th NCSB, Nordic Conference on Small Business Research, 2004.

REDIT, http//:www.redit.es 